\title{
Anxiolytic and anti-stress effects of acute administration of acetyl-L-carnitine in zebrafish
}

\author{
Lais Pancotto $^{1}$, Ricieri Mocelin ${ }^{2}$, Matheus Marcon ${ }^{2}$, Ana P Herrmann ${ }^{1}$, Angelo Piato ${ }^{\text {Corresp. } 1,2,3}$ \\ 1 Programa de Pós-Graduação em Farmacologia e Terapêutica, Universidade Federal do Rio Grande do Sul, Porto Alegre, RS, Brazil \\ 2 Programa de Pós-Graduação em Neurociências, Universidade Federal do Rio Grande do Sul, Porto Alegre, RS, Brazil \\ 3 Zebrafish Neuroscience Research Consortium (ZNRC), Los Angeles, United States \\ Corresponding Author: Angelo Piato \\ Email address: angelopiato@ufrgs.br
}

Studies have suggested that oxidative stress may contribute to the pathogenesis of mental disorders. In this context, molecules with antioxidant activity may be promising agents in the treatment of these deleterious conditions. Acetyl-L-carnitine (ALC) is a multitarget molecule that modulates the uptake of acetyl-CoA into the mitochondria during fatty acid oxidation, acetylcholine production, protein, and membrane phospholipid synthesis, capable of promoting neurogenesis in case of neuronal death. Moreover, neurochemical effects of ALC include modulation of brain energy and synaptic transmission of multiple neurotransmitters, including expression of type 2 metabotropic glutamate (mGlu2) receptors. The aim of this study was to investigate the effects of ALC in zebrafish by examining behavioral and biochemical parameters relevant to anxiety and mood disorders in zebrafish. ALC presented anxiolytic effects in both novel tank and light/dark tests and prevented the anxiety-like behavior induced by an acute stressor (net chasing). Furthermore, ALC was able to prevent the lipid peroxidation induced by acute stress in the zebrafish brain. The data presented here warrant further investigation of ALC as a potential agent in the treatment of neuropsychiatric disorders. Its good tolerability also subsidizes the additional studies necessary to assess its therapeutic potential in clinical settings. 


\section{Anxiolytic and anti-stress effects of acute administration of acetyl-L-carnitine in zebrafish}

2 Lais Pancotto ${ }^{1 \#}$, Ricieri Mocelin² ${ }^{2 \#}$, Matheus Marcon ${ }^{2}$, Ana P. Herrmann ${ }^{1}$, Angelo Piato ${ }^{1,2,3 *}$

3 'Programa de Pós-Graduação em Farmacologia e Terapêutica, Universidade Federal do Rio

4 Grande do Sul (UFRGS), Porto Alegre, RS, Brazil.

5 2Programa de Pós-Graduação em Neurociências, Universidade Federal do Rio Grande do Sul

6 (UFRGS), Porto Alegre, RS, Brazil.

$7 \quad$ 3Zebrafish Neuroscience Research Consortium (ZNRC), Slidell, LA, USA.

8 \#Both authors contributed equally to this article.

9

$10 *$ Correspondence to:

11 Angelo Piato, Ph.D.

12 Programa de Pós-Graduação em Farmacologia e Terapêutica, ICBS, Universidade Federal do

13 Rio Grande do Sul. Av. Sarmento Leite 500/305, Porto Alegre, RS, Brazil.

14 90050-170; Phone/Fax: +55 51 33083121; E-mail address: angelopiato@ufrgs.br 


\section{ABSTRACT}

16 Studies have suggested that oxidative stress may contribute to the pathogenesis of mental

17 disorders. In this context, molecules with antioxidant activity may be promising agents in the

18 treatment of these deleterious conditions. Acetyl-L-carnitine (ALC) is a multi-target molecule

19 that modulates the uptake of acetyl-CoA into the mitochondria during fatty acid oxidation,

20 acetylcholine production, protein, and membrane phospholipid synthesis, capable of promoting

21 neurogenesis in case of neuronal death. Moreover, neurochemical effects of ALC include

22 modulation of brain energy and synaptic transmission of multiple neurotransmitters, including

23 expression of type 2 metabotropic glutamate (mGlu2) receptors. The aim of this study was to

24 investigate the effects of ALC in zebrafish by examining behavioral and biochemical parameters

25 relevant to anxiety and mood disorders in zebrafish. ALC presented anxiolytic effects in both

26 novel tank and light/dark tests and prevented the anxiety-like behavior induced by an acute

27 stressor (net chasing). Furthermore, ALC was able to prevent the lipid peroxidation induced by

28 acute stress in the zebrafish brain. The data presented here warrant further investigation of ALC

29 as a potential agent in the treatment of neuropsychiatric disorders. Its good tolerability also

30 subsidizes the additional studies necessary to assess its therapeutic potential in clinical settings. 


\section{INTRODUCTION}

37

Acetyl-L-carnitine (ALC) facilitates the movement of acetyl-CoA into the mitochondria during the oxidation of fatty acids in mammals (Chapela et al., 2009). Moreover, this molecule is widely consumed as a dietary supplement for physical exercise (Ribas, Vargas \& Wajner, 2014; Nicassio et al., 2017). Recently, preclinical and clinical studies have demonstrated the effects of ALC on parameters relevant to anxiety, schizophrenia, and mood disorders; with onset of action faster than antidepressant drug and exert neuroprotective, neurotrophic, and analgesic effects (Levine et al., 2005; Wang et al., 2015; Traina, 2016; Singh et al., 2017; Nasca et al., 2017; Chiechio, Canonico \& Grilli, 2017).

A growing body of evidence suggests that psychiatric disorders such as anxiety and depression are associated with oxidative damage (Ortiz et al., 2017; Niedzielska et al., 2016; Schiavone, Colaianna \& Curtis, 2015; Cobb \& Cole, 2015; Ng et al., 2008), since a decrease in antioxidant capacity can impair the organism's protection against reactive oxygen species and cause damage to fatty acids, proteins, and DNA (Maes et al., 2011). Superoxide and hydroxyl radical (free radicals) or hydrogen peroxide and their derivatives (non-radical molecules) called reactive oxygen species (ROS) are responsible for causing oxidative damage (Smaga et al., 2015). The antioxidant defense mechanism they are the non-enzymatic (i.g. glutathione) and enzymatic antioxidants (i.g. superoxide dismutase and catalase) which show a trend to decrease in neuropsychiatric diseases (Ozcan et al., 2004; Hassan et al., 2016). Preclinical and clinical research has evaluated antioxidant compounds (i.g. N-acetylcysteine, resveratrol and curcumin) in the treatment of psychiatric disorders, and it has been reported that these compounds are able to protect against oxidative stress-induced neuronal damage, preventing lipid peroxidation and 
58 behavioral changes (Mecocci \& Polidori, 2012; Berk et al., 2014; Wang et al., 2014; Mocelin et 59 al., 2015; Patel, 2016; Santos et al., 2017). With simple, rapid and cheaper tests when compared with rodents, zebrafish have been

61 62 used as a powerful complementary model for the study of a variety of neuropsychiatric diseases through behavioral and biochemical parameters (Stewart et al., 2015; Mocelin et al., 2015; Marcon et al., 2016, 2018; Khan et al., 2017). There are several behavioral protocols extensively used and described for this species, such as the novel tank and light/dark tests. The novel tank diving test is based on an anti-predatory defense mechanism that induces fish to swim at the bottom of the tank, whereas the light/dark test evaluates anxiety based on the innate preference of adult zebrafish to dark over light areas (Levin, Bencan \& Cerutti, 2007; Gebauer et al., 2011; Khan et al., 2017; Pittman \& Piato, 2017).

In addition to its role in lipid metabolism, ALC also possesses free radical scavenging properties, and may thus protect the cells from oxidative damage by acting as an antioxidant (Gülçin, 2006; Sepand et al., 2016). Therefore, the aim of this study was to investigate the effects of ALC in zebrafish by examining behavioral and biochemical parameters relevant to anxiety and mood disorders in zebrafish.

MATERIALS AND METHODS Animals

240 adult zebrafish (Danio rerio, F. Hamilton 1822) wild-type short fin strain (6-monthold, 3-4 cm long) 50:50 male/female ratio were purchased from Delphis aquariums (Porto Alegre, Brazil). The fish were kept for 15 days in a closed acclimation tank system of $16 \mathrm{~L}$ ( $40 \mathrm{x}$ $20 \times 24 \mathrm{~cm}$ ) identical to the experimental tanks. Housing conditions consisted only of a tank with 
81 water, heater, filter and aeration system, and were maintained as previously described in Marcon

82 et al. (2016). The tanks contained non-chlorinated, aerated tap water $(\mathrm{pH} 7.0 \pm 0.3$; temperature

$8326 \pm 1^{\circ} \mathrm{C}$; total ammonia at $<0.01 \mathrm{mg} / \mathrm{L}$; nitrite $<0.01 \mathrm{mg} / \mathrm{L}$; dissolved oxygen at $7.0 \pm 0.4 \mathrm{mg} / \mathrm{L}$;

84 alkalinity at $22 \mathrm{mg} / \mathrm{L} \mathrm{CaCO}_{3}$ and total hardness at $5.8 \mathrm{mg} / \mathrm{L}$ ), with a light/dark cycle of $14 / 10 \mathrm{~h}$

85 (lights on at 06:00 am). The fish were fed twice a day with a commercial flake fish food (Alcon

86 BASIC $^{\circledR}$, Alcon, Brazil). On the experimental days, all the fish were only fed early in the

87 morning before behavioral testing began. The order of testing was counterbalanced so that

88 fasting time was randomized across experimental groups. All experiments were approved by the

89 Ethics Committee of Universidade Federal do Rio Grande do Sul (\#30992/2015).

\section{Drug and experimental design}

O-Acetyl-L-carnitine hydrochloride (ALC, CAS number 5080-50-2) was acquired from

Sigma-Aldrich (St Louis, Missouri, USA). In all experimental protocols (novel tank, light/dark, and acute chasing stress tests), the animals were treated or not with ALC $(0.1,1.0$ and 10.0 $\mathrm{mg} / \mathrm{L})$ in a beaker for 10 minutes. In the first protocol, immediately after the treatment, the animals were placed in the novel tank test (NTT) for 6 minutes. In the second protocol, after the treatments, the animals were placed in the light/dark test (LDT) for 5 minutes. Finally, in the third protocol, the animals were treated as previously and then chased with a net for 2 minutes. Then, the animals were placed in the NTT. The biochemical analyses were performed in animals

100 submitted to this last protocol. A control group was submitted to the same experimental

101 conditions (stressed or not) but without treatment. Different sets of animals were used in each

102 experimental protocol. The experimental design is shown in Figure 1 and was based on the

103 previously published study by Mocelin et al. (2015). All behavioral tests were performed 
104 between 09:00 am and 16:00 pm. The researchers who performed the behavioral tests and

105 analyzed the data were unaware of the allocation of animals to the experimental groups. The

106 concentrations were based on previous studies with another antioxidant compound (N-

107 acetylcysteine) and pilot studies with a wider concentration range. The same concentrations were

108 used in a chronic study with ALC (manuscript in preparation). We do not attempt to extrapolate

109 the drug concentrations we used in a fish study to human dosage since there is not a

110 straightforward calculation to be done. Since the half-life and other pharmacokinetic parameters

111 of ALC in zebrafish are not known, it is difficult to precisely compare the concentration range

112 that we observed here with the dose range for humans.

\section{Novel tank test (NTT)}

115 The novel tank test followed the protocol already described in Mocelin et al. (2015).

116 Briefly, the animals were separately moved to the apparatus $(2.7-\mathrm{L}$ tank, $24 \times 8 \times 20 \mathrm{~cm}$,

117 virtually divided into three equal horizontal zones and filled with standard tank water up to 15

$118 \mathrm{~cm}$ ) and video recorded for $6 \mathrm{~min}$ to be later analyzed by the ANY-maze ${ }^{\mathrm{TM}}$ software (Stoelting

119 Co., USA). To evaluate exploratory behavior and locomotion we measured the parameters: total

120 distance moved $(\mathrm{m})$, number of transitions between zones, time spent in the upper and bottom

121 zones of the tank, and number of transitions to the upper zone. Total distance and crossings were

122 used as an indicator of overall locomotor activity. The upper zone of the tank corresponds in rats

123 and mice protocols to the periphery region of the open-field test. Alterations in time spent and

124 number of crossings to this zone are frequently used as a parameter of anxiety in zebrafish

125 (Mocelin et al., 2015; Giacomini et al., 2016; Marcon et al., 2016; Mocelin et al., 2017; Marcon

126 et al., 2018). 
128 Light/dark test (LDT)

129 The light/dark test followed the protocol already reported by Gebauer et al. (2011).

130 Specifically, the apparatus consisted of a glass tank $(18 \times 9 \times 7 \mathrm{~cm})$ divided by a raised glass into

131 a dark and a white compartment of equal sizes, with the water level set at $3 \mathrm{~cm}$ and the partition

132 raised $1 \mathrm{~cm}$ above the tank floor. One fish at a time was positioned in the white zone of the

133 apparatus immediately after treatment. We recorded the number of crossings and the time spent

134 in the white compartment for $5 \mathrm{~min}$. Zebrafish have a natural preference for dark environments

135 and the white compartment is very anxiogenic for this species; anxiolytics increase the time

136 spent in the white compartment (Maximino et al., 2010; Mocelin et al., 2015).

137

138 Acute chasing stress test (ACS)

139 The acute stress protocol was performed according to the previous study published by

140 Mocelin et al. (2015). Briefly, the animals were treated for 12 minutes and then chased for the

141 last 2 minutes with a net before being moved to the novel tank, where they were recorded for 6

142 minutes. The behavioral parameters were quantified as described above for the NTT.

144 Tissue preparation

145 Samples were collected and prepared as previously reported by Mocelin et al. (2018).

146 Specifically, after the ACS fish were anesthetized by immersion in cold water and euthanized by

147 decapitation. Each independent sample was then obtained by pooling four brains, which were

148 homogenized on ice in $600 \mu \mathrm{L}$ phosphate buffered saline (PBS, pH 7.4, Sigma-Aldrich®). The 
149 homogenate was centrifuged at $10,000 \mathrm{~g}$ for $10 \mathrm{~min}$ at $4{ }^{\circ} \mathrm{C}$ in a cooling centrifuge, and the

150 supernatant was packed in microtubes for further assays.

151

\section{Protein determination}

153 Protein was determined by the Coomassie blue method described in detail by Bradford

154 (1976). Specifically, we used bovine serum albumin (Sigma-Aldrich $®$ ) as standard and the 155 absorbance of samples was measured at $595 \mathrm{~nm}$.

\section{Lipid peroxidation (TBARS)}

Lipid peroxidation was measured by the quantification of thiobarbituric acid reactive species (TBARS) production according to the method reported by (Draper \& Hadley, 1990). More specifically, we followed the protocol described by Mocelin et al. (2018), in which $50 \mu \mathrm{L}$

161 of the sample (80-100 $\mu$ g protein) was mixed with $75 \mu \mathrm{L}$ of trichloroacetic acid (TCA $10 \%$,

162 Sigma-Aldrich ${ }^{\circledR}$ ) and centrifuged at $6000 \mathrm{rpm}$ for $5 \mathrm{~min}$ at $4{ }^{\circ} \mathrm{C}$ in a cooling centrifuge. In the 163 supernatants were added to $75 \mu \mathrm{L}$ thiobarbituric acid (TBA $0.67 \%$, Sigma-Aldrich ${ }^{\circledR}$ ), then

164 homogenized in a vortex for $5 \mathrm{~s}$ and heated at $100^{\circ} \mathrm{C}$ for $30 \mathrm{~min}$. TBARS levels were measured

165 by absorbance $(532 \mathrm{~nm})$ in a microplate reader, using malondialdehyde (MDA, Sigma-Aldrich $\left.{ }^{\circledR}\right)$

166 as a standard, and results were expressed as nmol MDA/mg protein.

\section{Reduced thiol (SH) and Non-protein thiols levels (NPSH)}

169 SH and NPSH levels were determined and measured at $412 \mathrm{~nm}$ in a microplate reader

170 according to the method described by Ellman (1959). More specifically, we followed the steps

171 described by Mocelin et al. (2018). Briefly, for SH the samples (60-80 $\mu$ g protein) were added to 
$17210 \mathrm{mM}$ 5,5-dithio-bis-2-nitrobenzoic acid (DTNB) dissolved in ethanol, developing yellow color

173 after $1 \mathrm{~h}$. The NPSH were similarly assessed, except that the sample was mixed with equal

174 volumes of the $10 \%$ trichloroacetic acid (TCA) and centrifuged ( $6000 \mathrm{rpm}, 5 \mathrm{~min})$. The

175 supernatant was used for the biochemical assay. Results were expressed as $\mu \mathrm{mol} \mathrm{SH} / \mathrm{mg}$ protein.

176

177 Superoxide dismutase (SOD) and catalase (CAT) activities

178 SOD and CAT activities were determined according to the method reported by Misra \&

179 Fridovich (1972) and Aebi (1984), respectively. The protocol followed the more specific details

180 described by Dal Santo et al. (2014). Specifically, SOD activity was quantified in a microplate

181 reader $(480 \mathrm{~nm})$ by testing the inhibition of radical superoxide reaction of the sample $(20-30 \mu \mathrm{g}$

182 protein) in the presence of adrenalin, monitoring adrenochrome formation in a medium

183 containing a glycine- $\mathrm{NaOH}$ buffer $(\mathrm{pH} 10)$ and adrenaline (1 mM). CAT activity was assessed

184 by measuring the decrease in $\mathrm{H}_{2} \mathrm{O}_{2}$ absorbance in a microplate reader $(240 \mathrm{~nm})$. The assay

185 mixture consisted of sample ( $20-30 \mu \mathrm{g}$ protein), phosphate buffered saline (pH 7.4), and $5 \mu \mathrm{L}$

$186 \mathrm{H}_{2} \mathrm{O}_{2}(0.3 \mathrm{M})$. Results were expressed as units/mg protein.

187

188 Statistics

189 Normality and homogeneity of variance of the data were checked by D'Agostino-Pearson

190 and Levene tests, respectively. Results were analyzed by one- or two-way ANOVA followed by

191 Tukey's post hoc test. Two-way ANOVA was used to identify the main effects of stress and

192 treatment, as well as their interactions. Data are expressed as a mean + standard error of the

193 mean (S.E.M.). The level of significance was set at $\mathrm{p}<0.05$. 


\section{RESULTS}

\section{Behavioral parameters}

197 Figure 2 shows the effects of $\operatorname{ALC}(0.1,1.0$ and $10.0 \mathrm{mg} / \mathrm{L})$ on the novel tank test in

198 zebrafish. ALC significantly increased the time spent in the top (0.1 and $1.0 \mathrm{mg} / \mathrm{L}$, Fig. 2D) and

199 decreased the time spent the bottom $(0.1 \mathrm{mg} / \mathrm{L}$, Fig. $2 \mathrm{E})$ zone of the tank $\left(\mathrm{F}_{3,77}=8.0, \mathrm{p}=0.0001\right.$

200 and $\mathrm{F}_{3,77}=5.6, \mathrm{p}=0.0016$, respectively). Locomotor parameters of groups treated with $\operatorname{ALC}(0.1$,

201 1.0, and $10.0 \mathrm{mg} / \mathrm{L}$ ) did not differ from control (Fig. 2A and 2B).

202 In the light/dark test, $\operatorname{ALC}(0.1$ and $10.0 \mathrm{mg} / \mathrm{L})$ significantly increased the time spent in

203 the lit side of the tank when compared to control $\left(F_{3,92}=3.6, p=0.0161\right.$, Fig. 3B). The number of

204 crossings between the light and dark compartments was not altered by any of the concentrations

$205\left(\mathrm{~F}_{3,92}=0.9, \mathrm{p}=0.4284\right.$, Fig. 3A $)$.

206 Figure 4 shows the effects of ALC in the acute chasing stress (ACS) in zebrafish and

207 Table 1 summarizes the two-way ANOVA analysis. As expected, ACS decreased the distance

208 total traveled, crossings, entries and time in the top area (Fig. 4A, 4B, 4C, and 4D, respectively)

209 and increased the time in the bottom area (Fig. 4E). ALC (0.1, 1.0 and $10.0 \mathrm{mg} / \mathrm{L})$ prevented the

210 effects of ACS on the time in the top and bottom areas in the novel tank test (Fig. 4D and 4E).

211 Also, ALC $(0.1 \mathrm{mg} / \mathrm{L})$ prevented the effects of ACS on the total distance traveled.

212

\section{Biochemical parameters}

214 Figure 5 shows the effects of ALC $(0.1,1.0$ and $10.0 \mathrm{mg} / \mathrm{L})$ on oxidative status. ACS

215 significantly increased lipid peroxidation (TBARS), non-protein sulfhydryl (NPSH) and

216 superoxide dismutase (SOD) activity (Fig. 5A, 5C, and 5D, respectively), but did not alter

217 sulfhydryl (SH) content and catalase (CAT) activity (Fig. 5B and 5E, respectively). Treatment 
218 with ALC $(0.1,1.0$ and $10.0 \mathrm{mg} / \mathrm{L})$ prevented oxidative damage as measured by TBARS. ALC

219 also prevented the increase of antioxidant defenses as measured by NPSH $(0.1 \mathrm{mg} / \mathrm{L})$ and SOD

$220(0.1,1.0$ and $10.0 \mathrm{mg} / \mathrm{L})$. Two-way ANOVA analyses were summarized in Table 2.

221

\section{2}

223

224

225

226

227

228

229

230

231

232

233

234

235

236

237

238

239

240

241

\section{DISCUSSION}

Here, we showed for the first time that ALC presents anxiolytic effects in both novel tank and light/dark tests in zebrafish. Moreover, ALC was able to prevent the anxiogenic effects and lipid peroxidation induced by an acute stress protocol. These results indicate a potential use of ALC in mental disorders related to stress.

ALC increased the time spent in the upper as well as decreased the time spent in the bottom zones of the tank. Previous studies have shown that anxiolytic drugs such as buspirone, fluoxetine, diazepam, and ethanol increase the time spent in this zone (Bencan, Sledge \& Levin, 2009; Egan et al., 2009; Gebauer et al., 2011). In the light/dark test, ALC increased the time spent in the lit side of the tank. This effect was observed with other drugs as clonazepam, bromazepam, diazepam, buspirone, and ethanol (Gebauer et al., 2011). Additionally, multi-target drugs other than ALC, for instance, $\mathrm{N}$-acetylcysteine (NAC) and taurine, also increase the time in the lit side in the LTD in zebrafish (Mocelin et al., 2015; Mezzomo et al., 2015). In both NTT and LDT, ALC presented biphasic response. We can only speculate that different mechanisms of action may be involved in the effects of low versus high dose, but lower and higher concentrations would have to be tested for us to have a bigger picture of the dose-response relationship. ALC also prevented the locomotor impairment and anxiogenic behavior induced by the chasing stress protocol. Recently, our group has shown that fluoxetine, diazepam, and NAC prevented the effects of a similar stress protocol in zebrafish (Mocelin et al., 2015; Giacomini et al., 2016). 
243 (Levine et al., 2005; Wang et al., 2015; Lau et al., 2017). ALC modulates the cholinergic system

244 by increasing acetyl-CoA content and choline acetyltransferase activity. Moreover, it modulates

245 GABAergic, dopaminergic and glutamatergic neurotransmitter systems (Chapela et al., 2009;

246 Nasca et al., 2013; Wang et al., 2014; Singh et al., 2016; Chiechio, Canonico \& Grilli, 2017). In

247 rats, ALC decreased the immobility time in the forced swim test and increased sucrose

248 preference in 3 days of treatment, whereas 14 days were necessary to obtain the same effects

249 with clomipramine (Nasca et al., 2013).

250 Under normal conditions, damage by reactive oxygen species (ROS) is kept in control by

251 efficient antioxidant systems, such as SOD and CAT enzymes, as well as non-enzymatic

252 scavengers (Schiavone et al., 2013; Schiavone, Colaianna \& Curtis, 2015; Sandi \& Haller, 2015).

253 Studies have demonstrated that ALC protects cells against lipid peroxidation and membrane

254 breakdown through hydrogen peroxide scavenging (Kumaran et al., 2003; Gülçin, 2006), and can

255 promote the expression of antioxidant enzymes such as SOD and CAT (Augustyniak \&

256 Skrzydlewska, 2010; Li et al., 2012).

257 Even though the ACS protocol increased antioxidant defenses (NPSH and SOD), it also 258 caused lipid peroxidation (TBARS), which may indicate a possible adaptive response to ROS 259 production during stressful conditions. Similar results were observed in zebrafish and reported in 260 a previous study from our group using acute restraint stress (Dal Santo et al., 2014). Even though 261 detection of MDA levels by HPLC would be a more specific indicator of lipid peroxidation, the

262 TBARS assay we used in this study has been reported by many previous articles using samples 263 from zebrafish and other animals (Mihara \& Uchiyama, 1978; Sunderman et al., 1985; 264 Armstrong \& Browne, 1994; Yagi, 1998; Kim et al., 2011; Basu et al., 2014; Yavuzer et al., 
265 2016). The association of these factors could be related to the prevented effects of ALC, and that 266 our results indicate a deficit in antioxidant defenses against lipid peroxidation in zebrafish

267 submitted to the ACS protocol, providing further evidence for the hypothesis of an association

268 between behavior and ROS with the pathophysiology of mental disorders stress-related and their 269 prevention by ALC.

270

271 CONCLUSION

272

ALC is already widely used as supplementation for people who want to lose weight/fat 273 burner, but only a few studies assessed its effects on stress-related outcomes. In addition to its antioxidant actions, ALC is also able to restore mitochondrial function, which is relevant to 275 combat the dysregulation of fatty acid metabolism in the mitochondria-associated with 276 psychiatric disorders. Furthermore, there is evidence that ALC increases expression of metabotropic glutamate receptors via epigenetic mechanisms (Nasca et al., 2013), which is also relevant for the pathophysiology of depression and other stress-related disorders.

Our study adds to a growing body of literature demonstrating the role of antioxidants in modulating behavior and oxidative homeostasis. The data presented here thus warrants further investigation of ALC as a potential agent in the treatment of neuropsychiatric illness. Its novel mechanism of action and good tolerability also subsidize the additional studies necessary to assess its therapeutic potential in clinical settings. 


\section{REFERENCES}

289 de Abreu MS., Koakoski G., Ferreira D., Oliveira TA., da Rosa JGS., Gusso D., Giacomini ACV., Piato AL., Barcellos LJG. 2014. Diazepam and Fluoxetine Decrease the Stress Response in Zebrafish. PLoS ONE 9. DOI: 10.1371/journal.pone.0103232.

Armstrong D., Browne R. 1994. The analysis of free radicals, lipid peroxides, antioxidant enzymes and compounds related to oxidative stress as applied to the clinical chemistry laboratory. Advances in Experimental Medicine and Biology 366:43-58.

Augustyniak A., Skrzydlewska E. 2010. The influence of L-carnitine suplementation on the antioxidative abilities of serum and the central nervous system of ethanol-induced rats. Metabolic Brain Disease 25:381-389. DOI: 10.1007/s11011-010-9217-7.

Basu S., De D., Dev Khanna H., Kumar A. 2014. Lipid peroxidation, DNA damage and total antioxidant status in neonatal hyperbilirubinemia. Journal of Perinatology: Official Journal of the California Perinatal Association 34:519-523. DOI: 10.1038/jp.2014.45.

Bencan Z., Sledge D., Levin ED. 2009. Buspirone, chlordiazepoxide and diazepam effects in a zebrafish model of anxiety. Pharmacology, Biochemistry, and Behavior 94:75-80. DOI: 10.1016/j.pbb.2009.07.009.

Berk M., Dean OM., Cotton SM., Jeavons S., Tanious M., Kohlmann K., Hewitt K., Moss K., Allwang C., Schapkaitz I., Robbins J., Cobb H., Ng F., Dodd S., Bush AI., Malhi GS. 2014. The efficacy of adjunctive N-acetylcysteine in major depressive disorder: a doubleblind, randomized, placebo-controlled trial. The Journal of Clinical Psychiatry 75:628636. DOI: $10.4088 / \mathrm{JCP} .13 \mathrm{~m} 08454$. 
309 Chapela SP., Kriguer N., Fernández EH., Stella CA. 2009. Involvement of L-carnitine in cellular metabolism: beyond Acyl-CoA transport. Mini Reviews in Medicinal Chemistry 9:15181526.

312 Chiechio S., Canonico PL., Grilli M. 2017. 1-Acetylcarnitine: A Mechanistically Distinctive and Potentially Rapid-Acting Antidepressant Drug. International Journal of Molecular Sciences 19. DOI: 10.3390/ijms19010011.

315 Cobb CA., Cole MP. 2015. Oxidative and nitrative stress in neurodegeneration. Neurobiology of Disease 84:4-21. DOI: 10.1016/j.nbd.2015.04.020.

317 Dal Santo G., Conterato GMM., Barcellos LJG., Rosemberg DB., Piato AL. 2014. Acute

Draper HH., Hadley M. 1990. Malondialdehyde determination as index of lipid peroxidation. restraint stress induces an imbalance in the oxidative status of the zebrafish brain. Neuroscience Letters 558:103-108. DOI: 10.1016/j.neulet.2013.11.011. Methods in Enzymology 186:421-431.

Egan RJ., Bergner CL., Hart PC., Cachat JM., Canavello PR., Elegante MF., Elkhayat SI., Bartels BK., Tien AK., Tien DH., Mohnot S., Beeson E., Glasgow E., Amri H., Zukowska Z., Kalueff AV. 2009. Understanding behavioral and physiological phenotypes of stress and anxiety in zebrafish. Behavioural brain research 205:38-44.

327 Gebauer DL., Pagnussat N., Piato AL., Schaefer IC., Bonan CD., Lara DR. 2011. Effects of 328 anxiolytics in zebrafish: similarities and differences between benzodiazepines, buspirone and ethanol. Pharmacology, Biochemistry, and Behavior 99:480-486. DOI: 10.1016/j.pbb.2011.04.021. 
331 Giacomini ACVV., Abreu MS., Giacomini LV., Siebel AM., Zimerman FF., Rambo CL., 332 Mocelin R., Bonan CD., Piato AL., Barcellos LJG. 2016. Fluoxetine and diazepam acutely modulate stress induced-behavior. Behavioural Brain Research 296:301-310.

Gülçin I. 2006. Antioxidant and antiradical activities of L-carnitine. Life Sciences 78:803-811. DOI: 10.1016/j.bbr.2015.09.027.

337 DOI: 10.1016/j.1fs.2005.05.103.

Hassan W., Noreen H., Castro-Gomes V., Mohammadzai I., da Rocha JBT., Landeira-Fernandez J. 2016. Association of Oxidative Stress with Psychiatric Disorders. Current Pharmaceutical Design 22:2960-2974.

Khan KM., Collier AD., Meshalkina DA., Kysil EV., Khatsko SL., Kolesnikova T., Morzherin YY., Warnick JE., Kalueff AV., Echevarria DJ. 2017. Zebrafish models in neuropsychopharmacology and CNS drug discovery. British Journal of Pharmacology 174:1925-1944. DOI: 10.1111/bph.13754.

Kim H., Lee SW., Baek KM., Park JS., Min JH. 2011. Continuous hypoxia attenuates paraquatinduced cytotoxicity in the human A549 lung carcinoma cell line. Experimental \& Molecular Medicine 43:494-500. DOI: 10.3858/emm.2011.43.9.056.

Kumaran S., Deepak B., Naveen B., Panneerselvam C. 2003. Effects of levocarnitine on mitochondrial antioxidant systems and oxidative stress in aged rats. Drugs in $R \& D$ $4: 141-147$.

Lau T., Bigio B., Zelli D., McEwen BS., Nasca C. 2017. Stress-induced structural plasticity of medial amygdala stellate neurons and rapid prevention by a candidate antidepressant. Molecular Psychiatry 22:227-234. DOI: 10.1038/mp.2016.68. 
353 Levin ED., Bencan Z., Cerutti DT. 2007. Anxiolytic effects of nicotine in zebrafish. Physiology

354 \& Behavior 90:54-58. DOI: 10.1016/j.physbeh.2006.08.026.

355 Levine J., Kaplan Z., Pettegrew JW., McClure RJ., Gershon S., Buriakovsky I., Cohen H. 2005.

356 Effect of intraperitoneal acetyl-L-carnitine (ALCAR) on anxiety-like behaviours in rats. The International Journal of Neuropsychopharmacology 8:65-74. DOI: $10.1017 / \mathrm{S} 1461145704004596$.

359

360

361

362

363

364

365

366

367

368

369

370

371

372

373

374

Li J-L., Wang Q-Y., Luan H-Y., Kang Z-C., Wang C-B. 2012. Effects of L-carnitine against oxidative stress in human hepatocytes: involvement of peroxisome proliferator-activated receptor alpha. Journal of Biomedical Science 19:32. DOI: 10.1186/1423-0127-19-32.

Maes M., Galecki P., Chang YS., Berk M. 2011. A review on the oxidative and nitrosative stress (O\&NS) pathways in major depression and their possible contribution to the (neuro)degenerative processes in that illness. Progress in neuro-psychopharmacology \& biological psychiatry 35:676-692. DOI: 10.1016/j.pnpbp.2010.05.004.

Marcon M., Herrmann AP., Mocelin R., Rambo CL., Koakoski G., Abreu MS., Conterato GMM., Kist LW., Bogo MR., Zanatta L., Barcellos LJG., Piato AL. 2016. Prevention of unpredictable chronic stress-related phenomena in zebrafish exposed to bromazepam, fluoxetine and nortriptyline. Psychopharmacology Oct;233(21-22):3815-3824. DOI: $10.1007 / \mathrm{s} 00213-016-4408-5$.

Marcon M., Mocelin R., Benvenutti R., Costa T., Herrmann AP., de Oliveira DL., Koakoski G., Barcellos LJG., Piato A. 2018. Environmental enrichment modulates the response to chronic stress in zebrafish. The Journal of Experimental Biology Feb 22;221(1-7, Pt 4). DOI: $10.1242 /$ jeb. 176735 . 
375 Maximino C., Marques de Brito T., Dias CAG de M., Gouveia A., Morato S. 2010. Scototaxis as

376

377

378

379

380

381

382

383

384

385

386

387

388

389

390

391

392

393

394

395

396 anxiety-like behavior in fish. Nature Protocols 5:209-216. DOI: 10.1038/nprot.2009.225.

Mecocci P., Polidori MC. 2012. Antioxidant clinical trials in mild cognitive impairment and Alzheimer's disease. Biochimica et biophysica acta 1822:631-638. DOI: 10.1016/j.bbadis.2011.10.006.

Mezzomo NJ., Silveira A., Giuliani GS., Quadros VA., Rosemberg DB. 2015. The role of taurine on anxiety-like behaviors in zebrafish: A comparative study using the novel tank and the light-dark tasks. Neuroscience Letters Feb 2;613:19-24. DOI: 10.1016/j.neulet.2015.12.037.

Mihara M., Uchiyama M. 1978. Determination of malonaldehyde precursor in tissues by thiobarbituric acid test. Analytical Biochemistry 86:271-278.

Misra HP., Fridovich I. 1972. The role of superoxide anion in the autoxidation of epinephrine and a simple assay for superoxide dismutase. The Journal of Biological Chemistry $247: 3170-3175$.

Mocelin R., Herrmann AP., Marcon M., Rambo CL., Rohden A., Bevilaqua F., de Abreu MS., Zanatta L., Elisabetsky E., Barcellos LJG., Lara DR., Piato AL. 2015. N-acetylcysteine prevents stress-induced anxiety behavior in zebrafish. Pharmacology, Biochemistry, and Behavior Dec;139 Pt B:121-6. DOI: 10.1016/j.pbb.2015.08.006.

Mocelin R., Marcon M., D’ambros S., Herrmann AP., Araujo AS da R., Piato A. 2017. Behavioral and Biochemical Effects of N-Acetylcysteine in Zebrafish Acutely Exposed to Ethanol. Neurochemical Research Feb;43(2):458-464. DOI: 10.1007/s11064-0172442-2. 
397 Nasca C., Bigio B., Zelli D., de Angelis P., Lau T., Okamoto M., Soya H., Ni J., Brichta L., 398 Greengard P., Neve RL., Lee FS., McEwen BS. 2017. Role of the Astroglial Glutamate 399 Exchanger xCT in Ventral Hippocampus in Resilience to Stress. Neuron 96:402-413.e5. $400 \quad$ DOI: $10.1016 /$ j.neuron.2017.09.020.

401 Nasca C., Xenos D., Barone Y., Caruso A., Scaccianoce S., Matrisciano F., Battaglia G., Mathé 402 AA., Pittaluga A., Lionetto L., Simmaco M., Nicoletti F. 2013. L-acetylcarnitine causes 403 rapid antidepressant effects through the epigenetic induction of mGlu2 receptors. Proceedings of the National Academy of Sciences of the United States of America 405 110:4804-4809. DOI: 10.1073/pnas.1216100110.

406

407

408

Ng F., Berk M., Dean O., Bush AI. 2008. Oxidative stress in psychiatric disorders: evidence base and therapeutic implications. The International Journal of Neuropsychopharmacology 11:851-876. DOI: 10.1017/S1461145707008401.

Nicassio L., Fracasso F., Sirago G., Musicco C., Picca A., Marzetti E., Calvani R., Cantatore P., Gadaleta MN., Pesce V. 2017. Dietary supplementation with acetyl-1-carnitine counteracts age-related alterations of mitochondrial biogenesis, dynamics and antioxidant defenses in brain of old rats. Experimental Gerontology 98:99-109. DOI: 10.1016/j.exger.2017.08.017.

Niedzielska E., Smaga I., Gawlik M., Moniczewski A., Stankowicz P., Pera J., Filip M. 2016. Oxidative Stress in Neurodegenerative Diseases. Molecular Neurobiology 53:4094-4125. DOI: $10.1007 / \mathrm{s} 12035-015-9337-5$.

Ortiz GG., Pacheco Moisés FP., Mireles-Ramírez M., Flores-Alvarado LJ., González-Usigli H., Sánchez-González VJ., Sánchez-López AL., Sánchez-Romero L., Díaz-Barba EI., Santoscoy-Gutiérrez JF., Rivero-Moragrega P. 2017. Oxidative Stress: Love and Hate 
History in Central Nervous System. Advances in Protein Chemistry and Structural Biology 108:1-31. DOI: 10.1016/bs.apcsb.2017.01.003.

422 423 424 425 426 427 428 429 430 431 432 433 434 435 436 437 438 439 440

Ozcan ME., Gulec M., Ozerol E., Polat R., Akyol O. 2004. Antioxidant enzyme activities and oxidative stress in affective disorders. International Clinical Psychopharmacology 19:89-95.

Patel M. 2016. Targeting Oxidative Stress in Central Nervous System Disorders. Trends in Pharmacological Sciences 37:768-778. DOI: 10.1016/j.tips.2016.06.007.

Pittman J., Piato A. 2017. Developing Zebrafish Depression-Related Models. In: Kalueff AV ed. The rights and wrongs of zebrafish: Behavioral phenotyping of zebrafish. Cham: Springer International Publishing, 33-43. DOI: 10.1007/978-3-319-33774-6_2.

Ribas GS., Vargas CR., Wajner M. 2014. L-carnitine supplementation as a potential antioxidant therapy for inherited neurometabolic disorders. Gene 533:469-476. DOI: 10.1016/j.gene.2013.10.017.

Sandi C., Haller J. 2015. Stress and the social brain: behavioural effects and neurobiological mechanisms. Nature Reviews Neuroscience 16:290-304. DOI: 10.1038/nrn3918.

Santos P., Herrmann AP., Benvenutti R., Noetzold G., Giongo F., Gama CS., Piato AL., Elisabetsky E. 2017. Anxiolytic properties of N-acetylcysteine in mice. Behavioural Brain Research 317:461-469. DOI: 10.1016/j.bbr.2016.10.010.

Schiavone S., Colaianna M., Curtis L. 2015. Impact of early life stress on the pathogenesis of mental disorders: relation to brain oxidative stress. Current Pharmaceutical Design $21: 1404-1412$. 
441 Schiavone S., Jaquet V., Trabace L., Krause K-H. 2013. Severe life stress and oxidative stress in 442 the brain: from animal models to human pathology. Antioxidants \& Redox Signaling 443 18:1475-1490. DOI: 10.1089/ars.2012.4720.

444 445

Sepand MR., Razavi-Azarkhiavi K., Omidi A., Zirak MR., Sabzevari S., Kazemi AR., Sabzevari O. 2016. Effect of Acetyl-L-Carnitine on Antioxidant Status, Lipid Peroxidation, and Oxidative Damage of Arsenic in Rat. Biological Trace Element Research 171:107-115. DOI: $10.1007 / \mathrm{s} 12011-015-0436-\mathrm{y}$.

Singh S., Mishra A., Mishra SK., Shukla S. 2017. ALCAR promote adult hippocampal neurogenesis by regulating cell-survival and cell death-related signals in rat model of Parkinson's disease like-phenotypes. Neurochemistry International 108:388-396. DOI: 10.1016/j.neuint.2017.05.017.

Singh S., Mishra A., Srivastava N., Shukla R., Shukla S. 2016. Acetyl-L-Carnitine via Upegulating Dopamine D1 Receptor and Attenuating Microglial Activation Prevents Neuronal Loss and Improves Memory Functions in Parkinsonian Rats. Molecular Neurobiology Jan;55(1):583-602. DOI: 10.1007/s12035-016-0293-5.

Smaga I., Niedzielska E., Gawlik M., Moniczewski A., Krzek J., Przegaliński E., Pera J., Filip M. 2015. Oxidative stress as an etiological factor and a potential treatment target of psychiatric disorders. Part 2. Depression, anxiety, schizophrenia and autism. Pharmacological reports: PR 67:569-580. DOI: 10.1016/j.pharep.2014.12.015.

Stewart AM., Ullmann JFP., Norton WHJ., Parker MO., Brennan CH., Gerlai R., Kalueff AV. 2015. Molecular psychiatry of zebrafish. Molecular Psychiatry 20:2-17. DOI: 10.1038/mp.2014.128. 
463 Sunderman FW., Marzouk A., Hopfer SM., Zaharia O., Reid MC. 1985. Increased lipid 464 peroxidation in tissues of nickel chloride-treated rats. Annals of Clinical and Laboratory 465 Science 15:229-236.

466

467

468

469

470

471

472

473

474

475

476

477

478

479

480

481

482

483

484 485 Edition) 21:1314-1329.

Wang S-M., Han C., Lee S-J., Patkar AA., Masand PS., Pae C-U. 2014. A review of current evidence for acetyl-1-carnitine in the treatment of depression. Journal of Psychiatric Research 53:30-37. DOI: 10.1016/j.jpsychires.2014.02.005.

Wang W., Lu Y., Xue Z., Li C., Wang C., Zhao X., Zhang J., Wei X., Chen X., Cui W., Wang Q., Zhou W. 2015. Rapid-acting antidepressant-like effects of acetyl-l-carnitine mediated by PI3K/AKT/BDNF/VGF signaling pathway in mice. Neuroscience 285:281-291. DOI: 10.1016/j.neuroscience.2014.11.025.

Yagi K. 1998. Simple assay for the level of total lipid peroxides in serum or plasma. Methods in Molecular Biology (Clifton, N.J.) 108:101-106. DOI: 10.1385/0-89603-472-0:101.

Yavuzer H., Yavuzer S., Cengiz M., Erman H., Doventas A., Balci H., Erdincler DS., Uzun H. 2016. Biomarkers of lipid peroxidation related to hypertension in aging. Hypertension Research: Official Journal of the Japanese Society of Hypertension 39:342-348. DOI: 10.1038/hr.2015.156.

\section{Figure captions}

Figure 1. Schematic representation of the experimental protocol. Novel tank test (A), light/dark test (B), and acute chasing stress and biochemical assays (C). 
Figure 2. Effects of $\operatorname{ALC}(0.1,1.0$ and $10.0 \mathrm{mg} / \mathrm{L})$ on the distance traveled $(\mathrm{A})$, the number of crossings (B), entries (C) and time (D) in the upper zone, and time in the bottom zone (E) in the

Figure 3. Effects of $\operatorname{ALC}(0.1,1.0$ and $10.0 \mathrm{mg} / \mathrm{L})$ on the number of crossings $(\mathrm{A})$ and time in 492 the lit side (B) in the light/dark test in zebrafish. The data are presented as the mean + S.E.M. Oneway ANOVA followed by Tukey post hoc test. $n=18-27 .{ }^{*} p<0.05$ vs. control group. parameters in zebrafish. Distance traveled (A), number of crossings (B), entries (C) and time (D) in way ANOVA followed by Bonferroni's test. $\mathrm{n}=10-12 .{ }^{*} \mathrm{p}<0.05, * * * \mathrm{p}<0.001, * * * * \mathrm{p}<0.0001$ vs. control group (S-); ${ }^{\dagger} \mathrm{p}<0.05,{ }^{\dagger \dagger} \mathrm{p}<0.001,{ }^{\dagger \dagger \dagger} \mathrm{p}<0.0001$ vs. stressed control group (S+).

Figure 5. Effects of ALC pretreatment against stress-induced changes in biochemical parameters in zebrafish. Thiobarbituric acid reactive substances (A), sulfhydryl (B), non-protein sulphydryl (C), superoxide dismutase (D), and catalase, (E). The data are presented as the mean + group (S-); ${ }^{\dagger} \mathrm{p}<0.05,{ }^{\dagger \dagger} \mathrm{p}<0.001,{ }^{\dagger \dagger \dagger} \mathrm{p}<0.0001$ vs. stressed control group (S+). 
510 interaction between treatment with ALC and acute chasing stress.

511

512 Table 2. Results of two-way analysis of variance (ANOVA) of biochemical analysis and the 513 interaction between treatment with ALC and acute chasing stress. 
Figure 1

Schematic representation of the experimental protocol. Novel tank test (A), light/dark test (B), and acute chasing stress and biochemical assays (C).

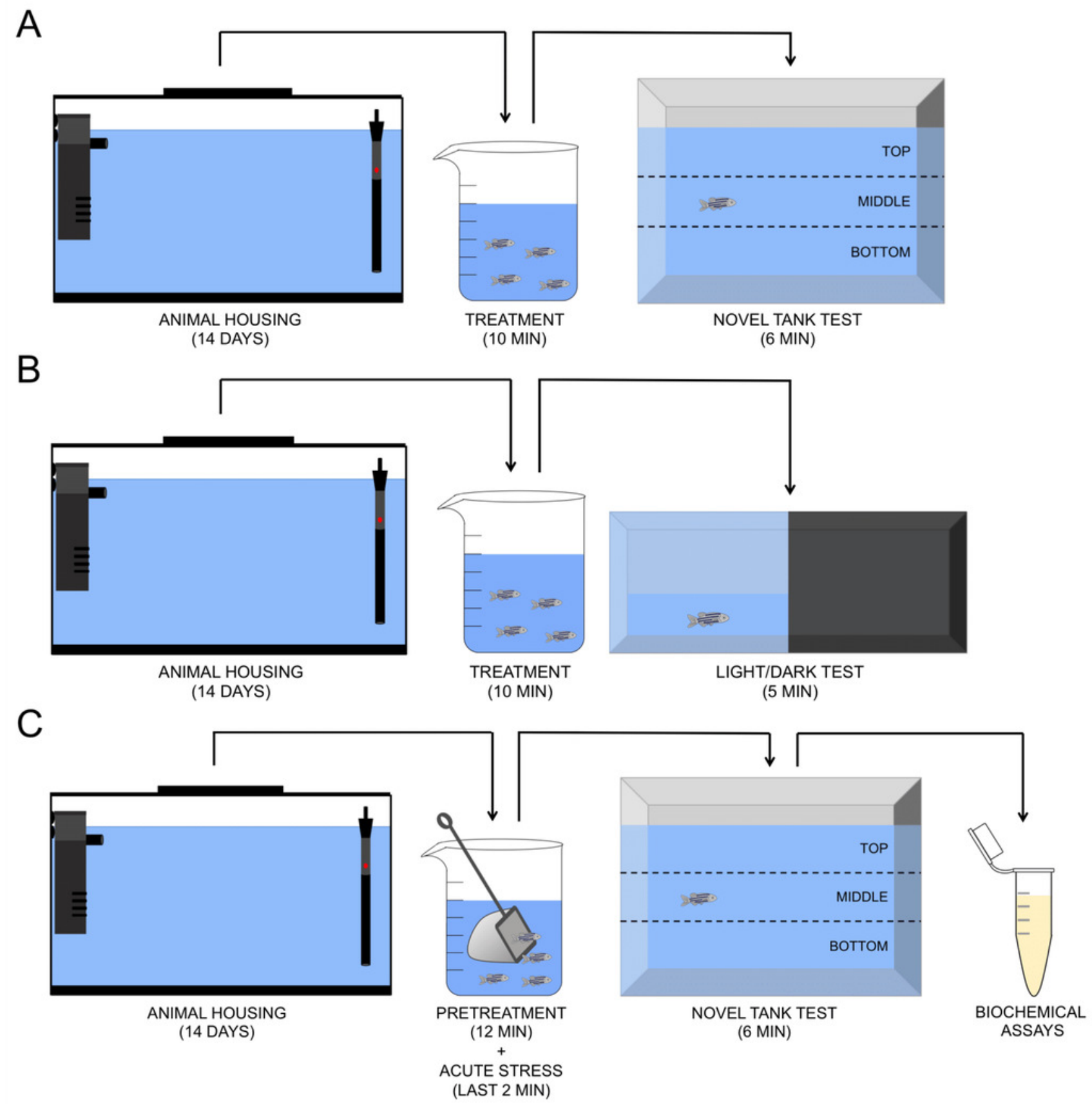


Figure 2 (on next page)

Effects of ALC $(0.1,1.0$ and $10.0 \mathrm{mg} / \mathrm{L})$ behavioral parameters in zebrafish submitted to the novel tank test.

(A) distance traveled, (B) number of crossings, (C) entries and (D) time in the upper zone, and (E) time in the bottom zone. The data are presented as the mean + S.E.M. One-way ANOVA followed by Tukey post hoc test. $\mathrm{n}=15-23 .{ }^{*} \mathrm{p}<0.05,{ }^{* *} \mathrm{p}<0.01,{ }^{* *} \mathrm{p}<0.001$ vs. control group. 
$A$

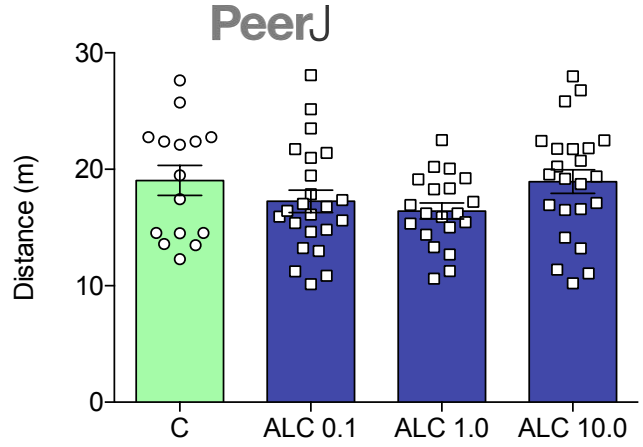

C

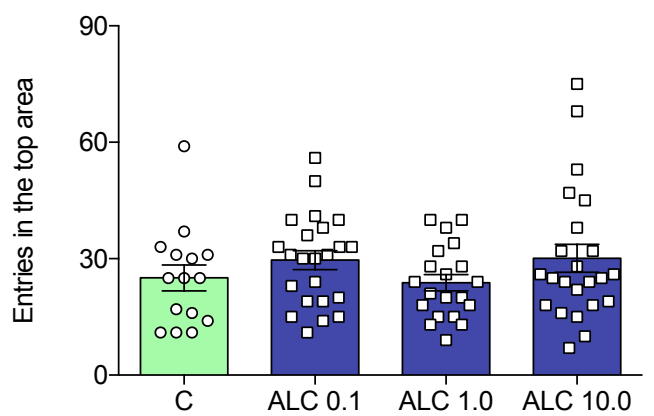

B Manuscript to be reviewed

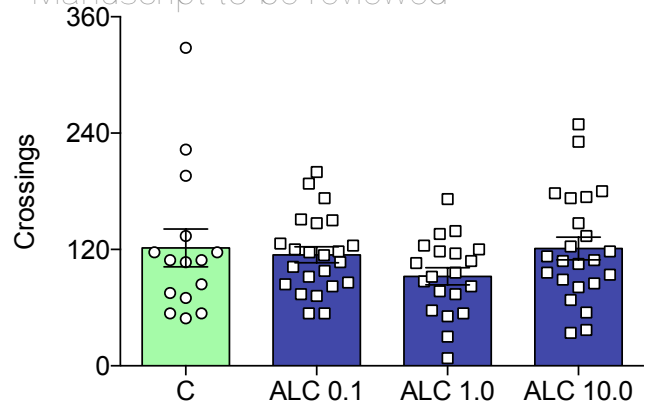

D

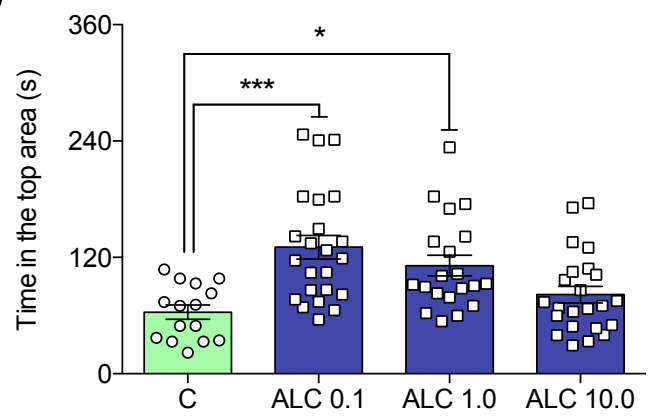

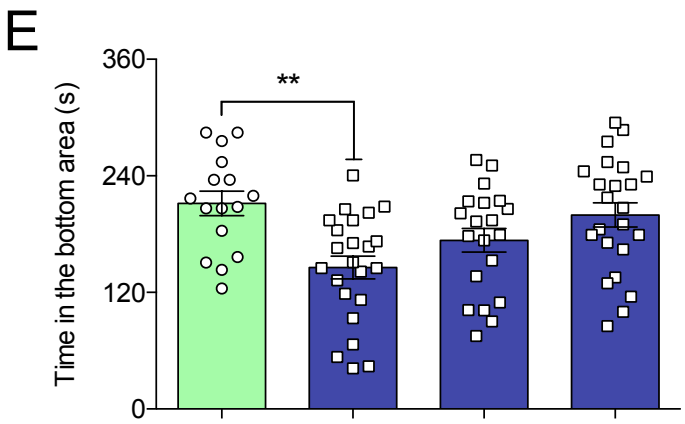

Peerf reviewing PDF | (2018:02:25046:3:0: NÊw 21 Jun 2Alls $0.1 \quad$ ALC 1.0 ALC 10.0 
Figure 3 (on next page)

Effects of ALC $(0.1,1.0$ and $10.0 \mathrm{mg} / \mathrm{L})$ in the light/dark test in zebrafish.

(A) number of crossings and (B) time in the lit side. The data are presented as the mean + S.E.M. One-way ANOVA followed by Tukey post hoc test. $n=18-27$. $* p<0.05$ vs. control group. 

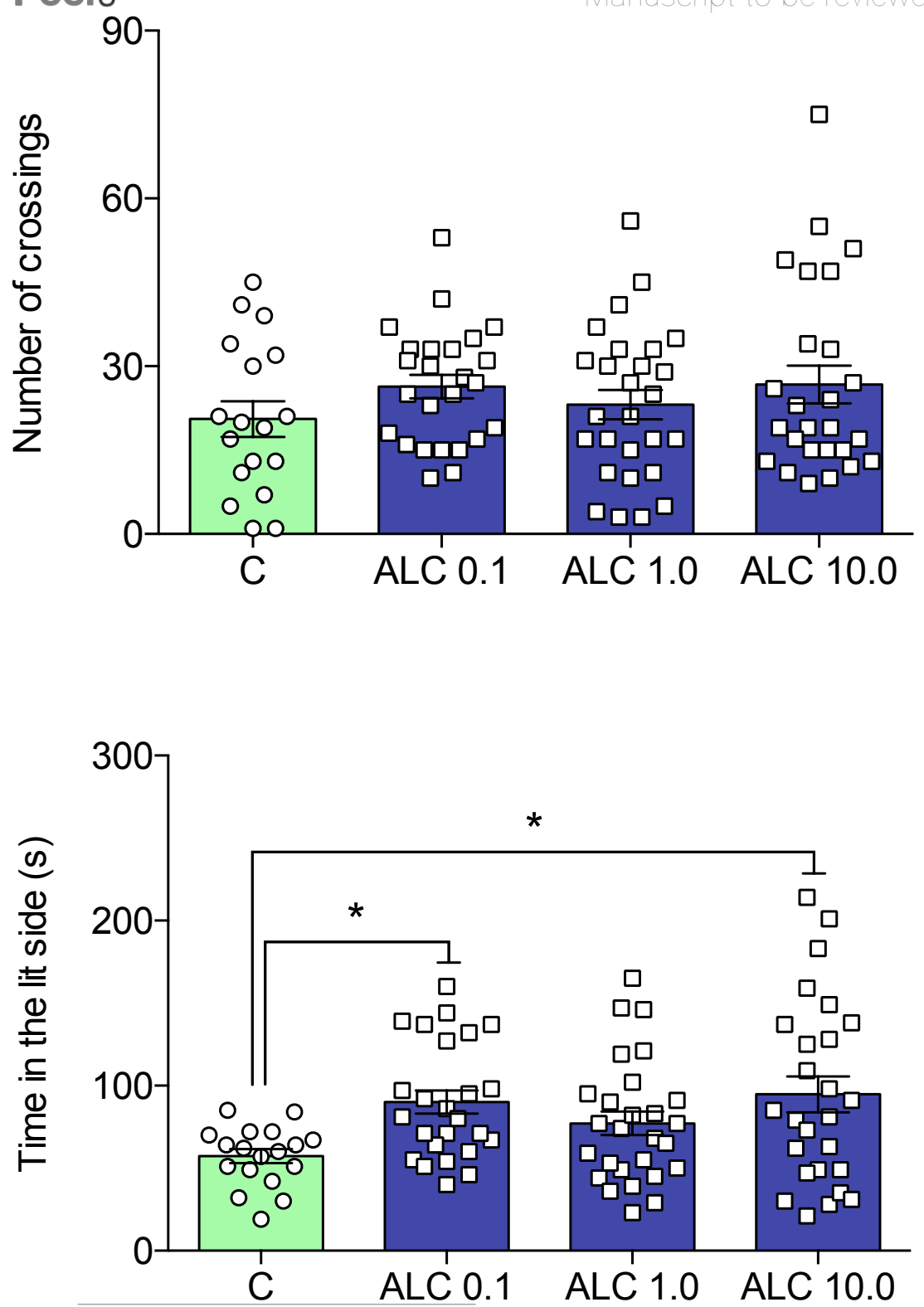
Figure 4(on next page)

Effects of ALC pretreatment against stress-induced changes in behavioral parameters in zebrafish.

(A) distance traveled, (B) number of crossings, (C) entries and (D) time in the upper zone, and (E) time in the bottom zone. The data are presented as the mean + S.E.M. Two-way ANOVA followed by Bonferroni's test. $\mathrm{n}=10-12$. ${ }^{*} \mathrm{p}<0.05,{ }^{* * *} \mathrm{p}<0.001,{ }^{* * * *} \mathrm{p}<0.0001$ vs. control group (S-); ${ }^{\dagger} p<0.05,{ }^{n+} p<0.001,{ }^{+1+} p<0.0001$ vs. stressed control group (S+). 
$A$

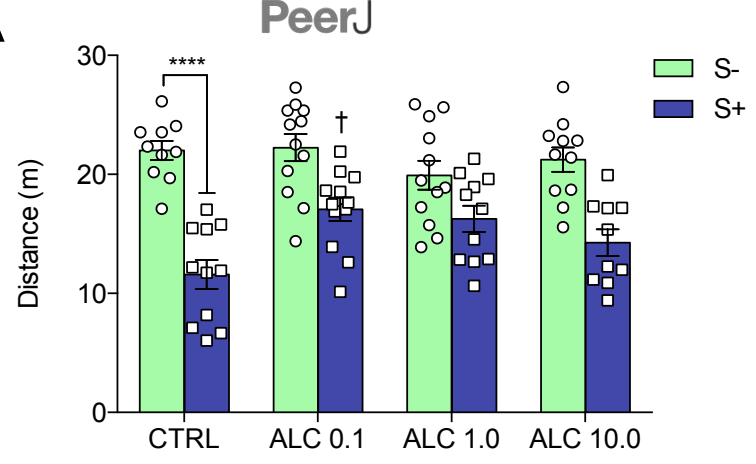

B Manuscript to be reviewed

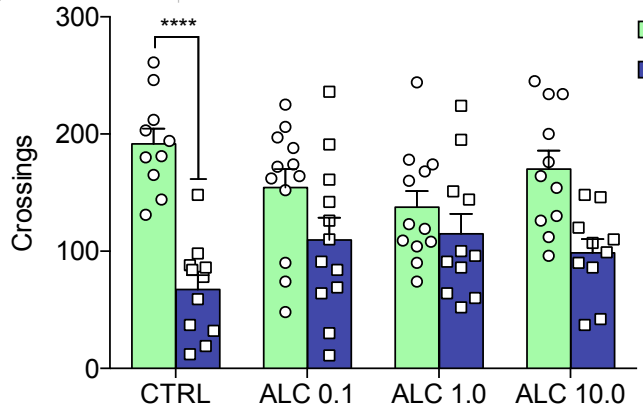

D

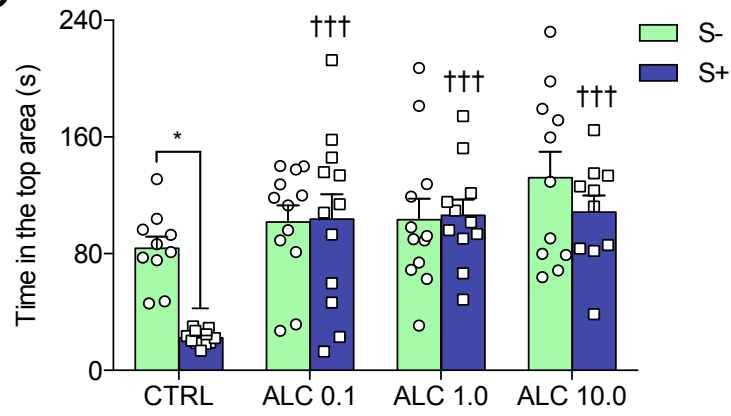

$\mathrm{E}$

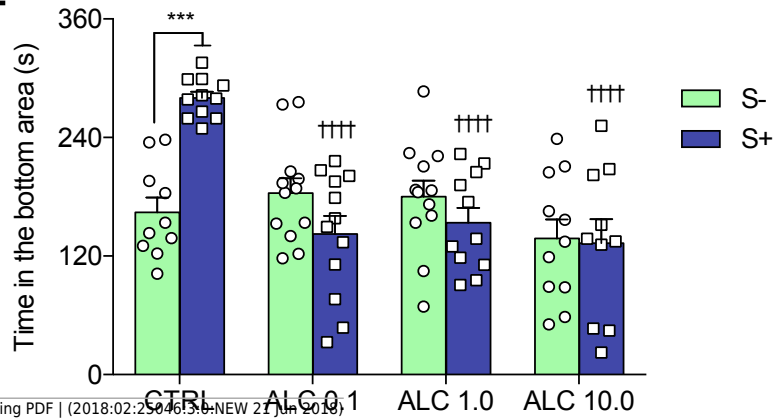


Figure 5 (on next page)

Effects of ALC pretreatment against stress-induced changes in biochemical parameters in zebrafish.

(A) thiobarbituric acid reactive substances, (B) sulfhydryl, (C) non-protein sulphydryl, (D) superoxide dismutase, and (E) catalase. The data are presented as the mean + S.E.M. Twoway ANOVA followed by Bonferroni's test. $n=3-4$. ${ }^{*} p<0.05, * * * p<0.001$ vs. control group (S-); ${ }^{t} p<0.05,{ }^{+1+} p<0.001,{ }^{+1+t} p<0.0001$ vs. stressed control group (S+). 
$A$

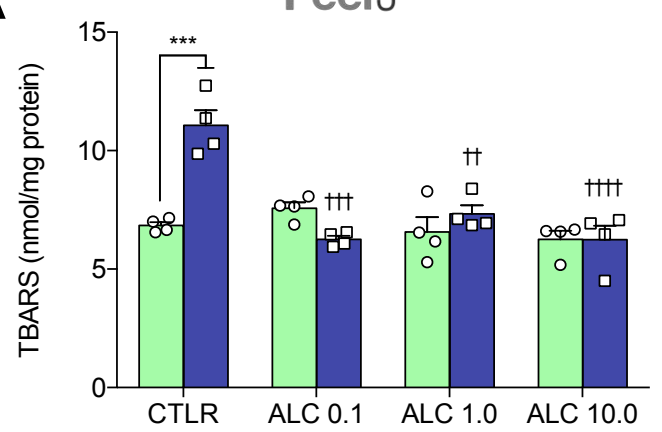

B Manuscript to be reviewed

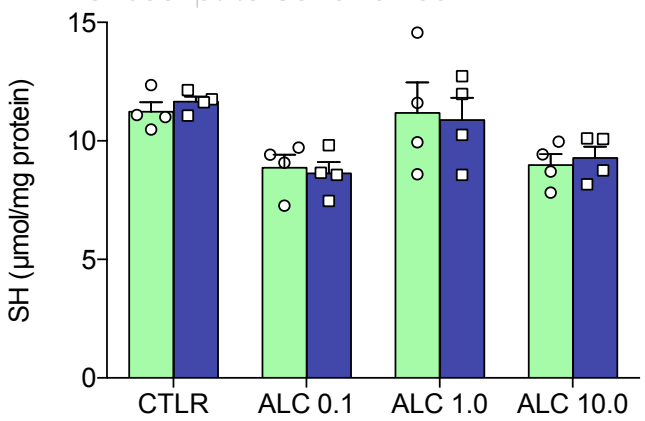

D

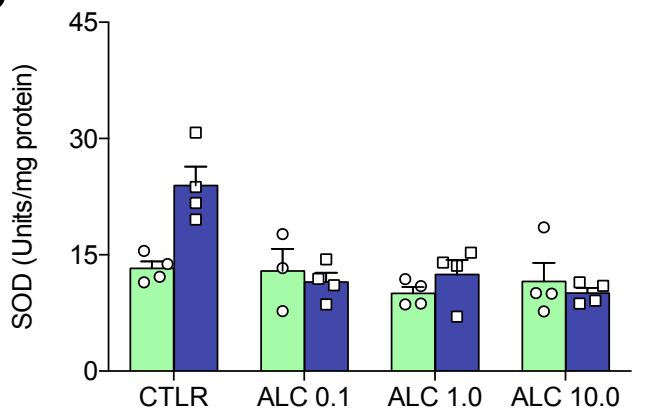

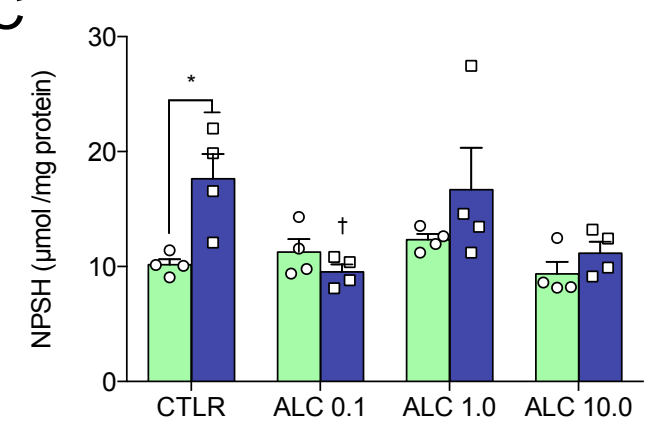

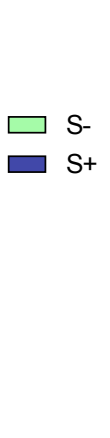

s.

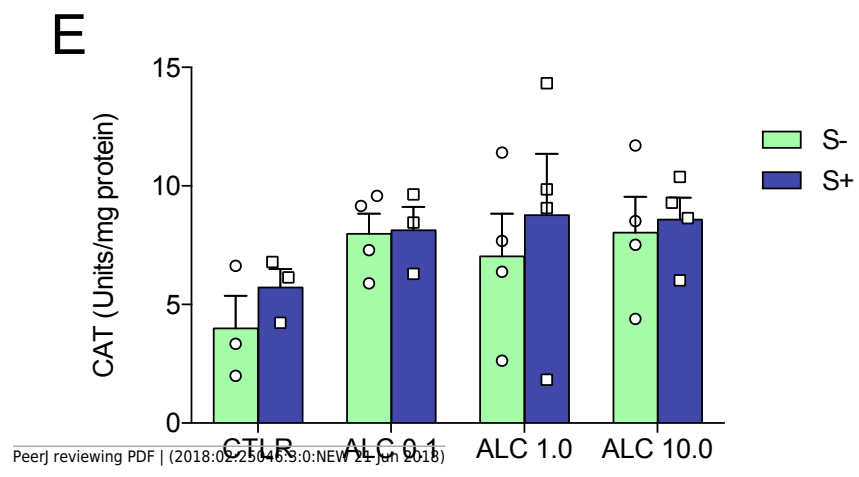




\section{Table $\mathbf{1}$ (on next page)}

Results of two-way analysis of variance (ANOVA) of behavioral analysis and the interaction between treatment with ALC and acute chasing stress.

$D F=$ degrees of freedom. Significant effects $(p<0.05)$ are given in bold font. 
1 Table 1:

2 Results of two-way analysis of variance (ANOVA) of behavioral analysis and the interaction

3 between treatment with ALC and acute chasing stress.

4

\begin{tabular}{lllll}
\hline Dependent variable & Effects & F-value & DF & P-value \\
\hline Total distance & Interaction & 3.46 & 3,81 & $\mathbf{0 . 0 2 0 1}$ \\
& ALC & 2.39 & 3,81 & 0.0745 \\
& Stress & 71.34 & 3,81 & $\mathbf{0 . 0 0 0 1}$ \\
\hline Crossings & Interaction & 4.04 & 3,81 & $\mathbf{0 . 0 0 9 9}$ \\
& ALC & 0.10 & 3,81 & 0.9583 \\
& Stress & 37.11 & 3,81 & $\mathbf{0 . 0 0 0 1}$ \\
\hline Entries in the top & Interaction & 3.47 & 3,81 & $\mathbf{0 . 0 1 9 8}$ \\
& ALC & 1.18 & 3,81 & 0.3215 \\
Time in the top & Stress & 36.10 & 3,81 & $\mathbf{0 . 0 0 0 1}$ \\
& Interaction & 2.72 & 3,81 & $\mathbf{0 . 0 4 9 9}$ \\
& ALC & 9.81 & 3,81 & $\mathbf{0 . 0 0 0 1}$ \\
& Stress & 4.86 & 3,81 & $\mathbf{0 . 0 3 0 3}$ \\
\hline Time in the bottom & Interaction & 9.02 & 3,81 & $\mathbf{0 . 0 0 0 1}$ \\
& ALC & 9.03 & 3,81 & $\mathbf{0 . 0 0 0 1}$ \\
& Stress & 0.84 & 3,81 & 0.3613 \\
\hline
\end{tabular}

$5 \mathrm{DF}=$ degrees of freedom. Significant effects $(\mathrm{p}<0.05)$ are given in bold font.

6 


\section{Table 2 (on next page)}

Results of two-way analysis of variance (ANOVA) of biochemical analysis and the interaction between treatment with ALC and acute chasing stress.

$D F=$ degrees of freedom. Significant effects $(p<0.05)$ are given in bold font. 
1 Table 2:

2 Results of two-way analysis of variance (ANOVA) of biochemical analysis and the interaction 3 between treatment with ALC and acute chasing stress.

4

\begin{tabular}{lllll}
\hline Dependent variable & Effects & F-value & DF & P-value \\
\hline Lipid peroxidation & Interaction & 14.70 & 3,24 & $\mathbf{0 . 0 0 0 1}$ \\
(TBARS) & ALC & 14.39 & 3,24 & $\mathbf{0 . 0 0 0 1}$ \\
& Stress & 8.80 & 1,24 & $\mathbf{0 . 0 0 6 7}$ \\
\hline Sulfhydryl & Interaction & 0.14 & 3,24 & 0.9339 \\
(SH) & ALC & 7.80 & 3,24 & $\mathbf{0 . 0 0 0 8}$ \\
& Stress & 0.01 & 1,24 & 0.9289 \\
\hline Non-protein thiol & Interaction & 2.73 & 3,24 & 0.0665 \\
(NPSH) & ALC & 3.63 & 3,24 & $\mathbf{0 . 0 2 7 3}$ \\
& Stress & 6.35 & 1,24 & $\mathbf{0 . 0 1 8 8}$ \\
\hline Superoxide dismutase & Interaction & 5.46 & 3,23 & $\mathbf{0 . 0 0 5 5}$ \\
(SOD) & ALC & 9.93 & 3,23 & $\mathbf{0 . 0 0 0 4}$ \\
& Stress & 4.26 & 1,23 & 0.0504 \\
\hline Catalase & Interaction & 0.13 & 3,21 & 0.9393 \\
(CAT) & ALC & 1.89 & 3,21 & 0.1626 \\
& Stress & 0.87 & 1,21 & 0.3606
\end{tabular}

$5 \mathrm{DF}=$ degrees of freedom. Significant effects $(\mathrm{p}<0.05)$ are given in bold font.

6 